African Crop Science Journal by African Crop Science Society is licensed under a Creative Commons Attribution 3.0 Uganda License. Based on a work at www.ajol.info/ and www.bioline.org.br/cs DOI: http://dx.doi.org/10.4314/acsj.v25i1.3S

\title{
PARTICIPATORY RESEARCH DEMONSTRATION AND ITS IMPACT ON THE ADOPTION OF IMPROVED AGRICULTURAL TECHNOLOGIES IN THE SAVANNAS OF WEST AFRICA
}

\author{
L. OLARINDE, J. BINAM ${ }^{1}$, A.O. FATUNBI ${ }^{2}$, A. DIAGNE ${ }^{3}$, A. ADEKUNLE ${ }^{2}$ and A. AYANWALE ${ }^{4}$ \\ Department of Agricultural Economics, Ladoke Akintola University of Technology, P.M.B. 4000 Ogbomoso, \\ Oyo State, Nigeria \\ ${ }^{1}$ World Agroforestry Center (ICRAF), Bamako, Mali \\ ${ }^{2}$ Forum for Agricultural Research In Africa, Accra, Ghana \\ ${ }^{3}$ Africa Rice Center, Cotonou, Benin Republic \\ ${ }^{4}$ Obafemi Awolowo University, Ile-Ife, Nigeria \\ Corresponding author: lolarinde@yahoo.com, loolarinde@lautech.edu.ng
}

\begin{abstract}
Despite continued progress in the development and promotion of improved agricultural technologies, and the gradual process in agricultural research for development (R4D) programmes, adoption rates are relatively low in most parts of sub-Saharan Africa (SSA). Recommendations have, therefore, been made by national and international research institutions and stakeholders for more involvement of the smallholders in evaluating promising agricultural technologies. This study assessed the impact of the participatory research demonstration on the adoption of the technologies promoted by the sub-Saharan Africa Challenge Programme (SSACP) using the innovation platform (IP) concept. Results showed that 67 and 59\% of the IP and non-IP farmers, respectively, reported that researchers and extension personnel decided on the technologies for research or demonstration. Fifty-two and $43 \%$ of the IP and non-IP farmers, respectively, perceived research and demonstration to be very useful. The type of technology or demonstration that farmers mostly participated in was crop variety (IP farmers $=72.87 \%$; non-IP farmers=70.19\%). Following our analyses which are based on the Instrumental Variable (IV) approach, participation in research and demonstrations significantly increased adoption of the demonstrated technologies by $99 \%$. We observed a $100 \%$ significant increase in adoption of the demonstrated technologies in the sample of IP participants. The main factors that determined the adoption of the demonstrated technologies included membership to farmer group, and distances to input and output markets.
\end{abstract}

Key Words: Innovation Platforms, Research for Development, SSA CP

\section{RÉSUMÉ}

Malgré les progrès continu dans le développement et la promotion des technologies agricoles améliorées, le progrès graduel dans les programmes de recherche agricole pour le développement (R4D), les taux d'adoption sont relativement faibles dans la plupart des parties de l'Afrique Sub-Saharienne (SSA). Des recommendations ont été, cependant faites par les institutions nationales et internationals de recherches et les parties prenantes pour plus d'implication des petits exploitants agricoles dans l'évaluation des technologies agricoles prometteuses. Cette étude a evalué l'impact de la démonstration de la recherche participative sur l'adoption des technologies dévelopées par le programme d'enjeu de l'Afrique Sub-Saharienne (SSA CP) en utilisant le concept de la plateforme d'innovation (IP). Les résultats ont montré que 67 et $59 \%$ des producteurs de IP et non-IP, respectivement, ont rapporté que les chercheurs et le personnel de vulgarisation ont le pouvoir de décision sur les technologies de recherche et de démonstration. Cinquante-deux et $43 \%$ de producteurs IP et non-IP, respectivement, ont perçu la 
recherche et la démonstration comme très utiles. Le type de technologie ou de démonstration auquel les paysans ont participé était la variété de culture, (producteurs $\mathrm{IP}=72,87 \%$; producteurs non-IP=70,19\%). Selon nos analyses qui sont basées sur l'approche de variable instrumentale (IV), la participation à la recherche et à la demonstration a sigificativment augmenté l'adoption des technologies démontrées par $99 \%$. Nous avions observé une augmentation significative de $100 \%$ d'adoption de technologies démontrées dans l'échantillon des particpants IP. Les facteurs principaux qui déterminent l'adoption des technologies démontrées comprennent l'appartenance aux groupements de producteurs, et les écarts entre les marchés d'intrant et du produit.

Mots Clés: Plate-formes d'innovation, recherche pour le développement, SSA CP

\section{INTRODUCTION}

Participatory methodologies have become important in public agricultural research in recent years. These approaches aim at overcoming barriers that separate researchers from the economically and socially disadvantaged communities where they serve, to engage in all the collaborative identification. They are also aimed at studying local problems, with the ultimate goal of taking action to improve local conditions (Gaventa, 1988; Chambers, 1997).

The fundament planning activities, conducting on-farm trials and the evaluation of the planning and trials is based on "learning by doing", involving researchers, extension workers and farmers. This implies that the farmers play an important role in the research and development process, starting from the identification of the problems, through planning activities, conducting on-farm trials, evaluating the trials, and providing feedback to the appropriate stakeholders.

Implementing farmer participatory research (FPR) activities requires the involvement of multidisciplinary teams that are able to identify the problems existing at community level. This kind of activity allows both researcher and extension worker to get more information about the farmers' community in a very short period of time. Such interaction makes researchers and extension workers not mere technology transfer agents, but also persons who learn from the other participating stakeholders.

The above background describes one of the extension approaches that has been adopted by national, regional, international and many other development institutions to improve smallholders' awareness and in effect adoption of improved agricultural technologies (Johnson et al., 2004). Although the concept of participatory development attained high levels of legitimacy in the international community, gaps between participatory rhetoric and participatory practice remain (Nelson and Wright, 1995; Gonsalves et al., 2005; Ghimire, 2009).

Development organisations seek to effectively apply participatory approaches, but struggle with the implementation and institutionalisation of these approaches into day-to-day practice (Thompson, 1995). To date, research into the effective institutionalisation of community participation in rural development has been limited (Buchy et al., 2000). As extension practitioners seek to institute participatory practices, there remains a crucial need for research that identifies factors contributing to successful implementation of participatory practices (Chambers, 1994).

By way of participatory research, the subSaharan African Challenge Programme (SSA $\mathrm{CP})$, through its implementation of the Integrated Agricultural Research for Development (IAR4D), has been promoting a series of agricultural research actions to improve upon the ways in which the traditional agricultural research and development has been conducted. One of the ways it does this is by making research all inclusive; more importantly, by involving all the stakeholders, especially the small scale farmers in the ways research in agriculture is conducted. The 
primary objective of this paper is to evaluate the impact of participatory research demonstration on the adoption of improved agricultural technologies in the Savannas of West Africa, where one of the SSA CP's Pilot Learning Sites (PLS) is sited.

Participatory research. Much of the literature on participatory research falls into two broad categories (Lilja and Bellon, 2006): (i) papers that describe types of participatory research (Biggs, 1989; Biggs and Farrington, 1991; Pretty, 1994); and (ii) studies that describe participatory tools and how to use them (Farrington, 1988; Chambers et al., 1989; Okali et al., 1994; Pretty, 1994; Chambers, 1997; Campbell, 2001). There are no specific standards to guide research managers, nor guidelines for deciding when participatory approaches will result in greater benefits to farmers or other intended beneficiaries, than conventional research. Studies claim that participatory methods are crucial in programmes that require holistic approaches (rather than changing one technology at a time), and where environmental and socio-economic conditions vary widely among farmers and sites (Roling and Wagemakers, 1998). But few published studies provide definite decision-rules, based on empirical evidence, about when participatory approaches are more beneficial than traditional, centralised approaches. Some studies show that traditional, scientistdesigned and -directed research programmes are very effective at developing varieties and technologies that can be used in homogenous farming systems, but often less effective when the reality of the farmer is more complex and risk-prone (Byerlee and Heisey, 1996; Maredia et al., 1998; Evenson and Gollin, 2002; Dalton and Guei, 2003).

In reality, participatory research is often tried or used when conventional approaches for developing improved crop varieties or natural-resource management practices fail, often with resource-poor farmers. There are various reasons for the low uptake of agricultural technologies produced and promoted through conventional systems. Nowak (1992) advances two types of barriers to adoption as (i) the inability to adopt, which stems from the lack of access to information about the technology; and (ii) the unwillingness to adopt, which is due to the fact that conflicting or inconsistent information is provided about the new technology. Here, information about the technology may also be difficult to apply or irrelevant.

Studies such as of Weltzein et al. (2000) and Johnson et al. (2004) provide insights into the question of when to use participatory research approaches. These studies hinged on mapping 65 participatory plant-breeding projects, on a matrix of biophysical and economic factors. The mapping involved shaping the project environment, which comprised of 59 participatory natural resource management projects, among which the most common resource was soil. Therefore, nearly half the projects focused on soil-related topics.

The above studies also found great variation in research objectives, reasons for involving various stakeholders in the research process, intended users or beneficiaries, duration of the project, geographical focus of the projects as well as other scale measures of the project.

Participatory research and agricultural technology adoption. Many public and private agricultural research institutions have now adopted the use of participatory research models as a way of generating and sustaining rapid innovation in a highly uncertain and variable environment (Johnson et al., 2003). Studies have shown that projects that allow resource-poor farmers to choose and design appropriate technologies usually result in better outcomes. An example is found in Lilja and Bellon (2006) where the approach helped farmers to survive harsh drought-and-pest prone conditions. Success is often not found in the agricultural technology itself, but it is grounded in building human and social capital, confidence, knowledge, networks and capacity; which allows technologies to have 
an effect on livelihoods. The challenge is how to scale up these individual successful projects to larger scale.

The challenging question is "Can or should the pipeline model of agricultural innovation and participatory model effectively co-exist in a public agricultural research institution (Morris and Bellon, 2004)" It can be argued that scaling impact of the agricultural research that benefits the poor requires change in the way in which the current agricultural innovation system is organised (Rhoades, 2005). A shift from pipeline agricultural research model to participatory research and extension does not just require adoption of a simple set of techniques such as participatory rural appraisal, farmer visits, farmer evaluations, and farmer experiments; these are necessary but not sufficient conditions. It will also require an organisational change process to occur (Biggs, 2003). Most importantly, a parallel process must occur in user organisations, that is, in National Agricultural Research Stations (NARS) and local farmer organisations.

Agricultural technology adoption pathway. Farmer's decision to adopt a technology is separate from the decision to participate in the project activities, since participants can choose not to adopt and non-participants can choose to adopt the varieties (Lilja and Dixon, 2011). However, the decisions are not independent because some of the same factors that influence the decision to participate are likely also to influence the decision to adopt. The methodological challenge to measuring the impact of participation from the impact of adoption of technology itself requires specification of an econometric model that separates the technology effects from the knowledge effects to be assumed from farmer participatory research. The household Theory can serve as the general conceptual framework to measure impacts of technology adoption and knowledge. Therefore, a household utility function with a multi-product production function, including commodity and non- commodity outputs, needs to be formulated, and knowledge can be included as a stock resource to be enhanced by project participation (Dalton et al. 2005).

When measuring the adoption, both behavioral (changes in area planted, changes in area under new variety, etc.) and productivity (e.g. change in yields) outcomes need to be considered. Since some of the same farm and farmer characteristics that affect participation and adoption will also likely influence land allocation and production, the empirical analysis must be done via estimations of sets of simultaneous equations. Functional participation, as discussed earlier, does not challenge impact-assessment methodology.

Whether or not there is farmer participation in the technology development process, agronomical outcomes can be assessed in terms of both yield changes, loss of soil or soil nutrients and/or changes in pest or weed pressure. Economically, the sustainability of cropping systems can be assessed at the farm level by looking at net income over time, amenity gains, increased positive externalities or mitigating negative externalities such as soil erosion or nutrient loading. Involving farmers may increase or decrease costs during the technology development process (Lilja and Aw-Hassan, 2003; Johnson et al., 2004) and considerably depends on whether or not the participatory activities replace activities in the conventional research process or if they are included as "add on" activities; therefore generating additional costs.

Once developed, however, the technologies are typically diffused through conventional channels. Empowering participation does have significant implications on how impacts are generated and measured (Dalton et al., 2005). As with conventional technologies, benefits can still be quantified in terms of increased agricultural productivity or reduced environmental damage; however, the sources of the benefits are of two types. Part of any observed increase in productivity can be attributed directly to the superiority of the new 
technology or practice. These are often referred to as "embodied" effects, since they are part of the technology itself (Chambers, 1988). The second source of improved productivity is the increased knowledge or capacity that the farmer obtains by participating in the research process. These are often referred to as "disembodied" effects, because they are not part of the technology. These two types of impacts are not independent, since a more knowledgeable farmer can make better use of a new technology. Therefore, it is important to be able to separate the embodied and disembodied effects in order to accurately evaluate the impact of both the participatory research process and the technology.

For this research, we are concerned about "Participatory Research" which in our opinion, serves as one of the basis for the agenda of the IAR4D and an agent to achieving the four key objectives of (i) developing technologies for the sustainable intensification of subsistence-oriented farming systems; (ii) developing smallholder production systems that are compatible with sound natural resource management; (iii) improving the accessibility and efficiency of markets for smallholder and pastoralist products; and (iv) promoting the formulation and adoption of policies that encourage innovation and will lead to improved livelihoods for smallholders.

Participatory research or technology demonstration in the Kano-Katsina-Maradi pilot learning site (KKM PLS) is carried out in few of the severally available and known ways (Fig. 1). For the fact that most of the technologies promoted in the KKM are not totally new, research or technology demonstrations are done in such a way that stakeholders are taught or made to see the improvement that has been made on the familiar ones, and how the knowledge about them can be used to improve upon their use and in case of crop varieties, their cultivation. Therefore, the technologies are demonstrated in a participatory manner during farmer field days, training, and in most cases, in community mobilisation preparatory to the cropping/planting season.

\section{METHODOLOGY}

Analytical framework. The framework adopted in the analysis of the data involved two steps. In the first step, descriptive analyses were carried out on the viewpoints of the respondents on the following:

(i) who decided on the technologies to be researched on or demonstrated;

(ii) role of respondents in the research/ demonstration;

(iii) perception of respondents on the usefulness of the research/demonstration and (iv) reasons for the non-adoption of the technologies demonstrated. Respondents were also asked to provide answers to questions concerning their roles in the research/demonstration.

Answers to these questions were also subjected to descriptive analysis.

In the second step, an impact evaluation model was applied. An impact evaluation model is essential in light of missing data. This is because one cannot observe the outcomes of the participants of a programme if they have not been beneficiaries (Cameron and Trivedi 2005; Imbens and Wooldridge, 2009; Khandker et al., 2010). Without information on the counterfactual, the next best alternative is to compare outcomes of treated individuals or households with those of a comparison group that has not been treated. In doing so, one attempts to pick a comparison group that is very similar to the treated group, such that those who received the treatment would have had outcomes similar to those in the comparison group in the absence of treatment. Different methods can be used in impact evaluation theory to address the fundamental question of the missing counterfactual. Each of these methods carries its own assumptions about the nature of potential selection bias in 


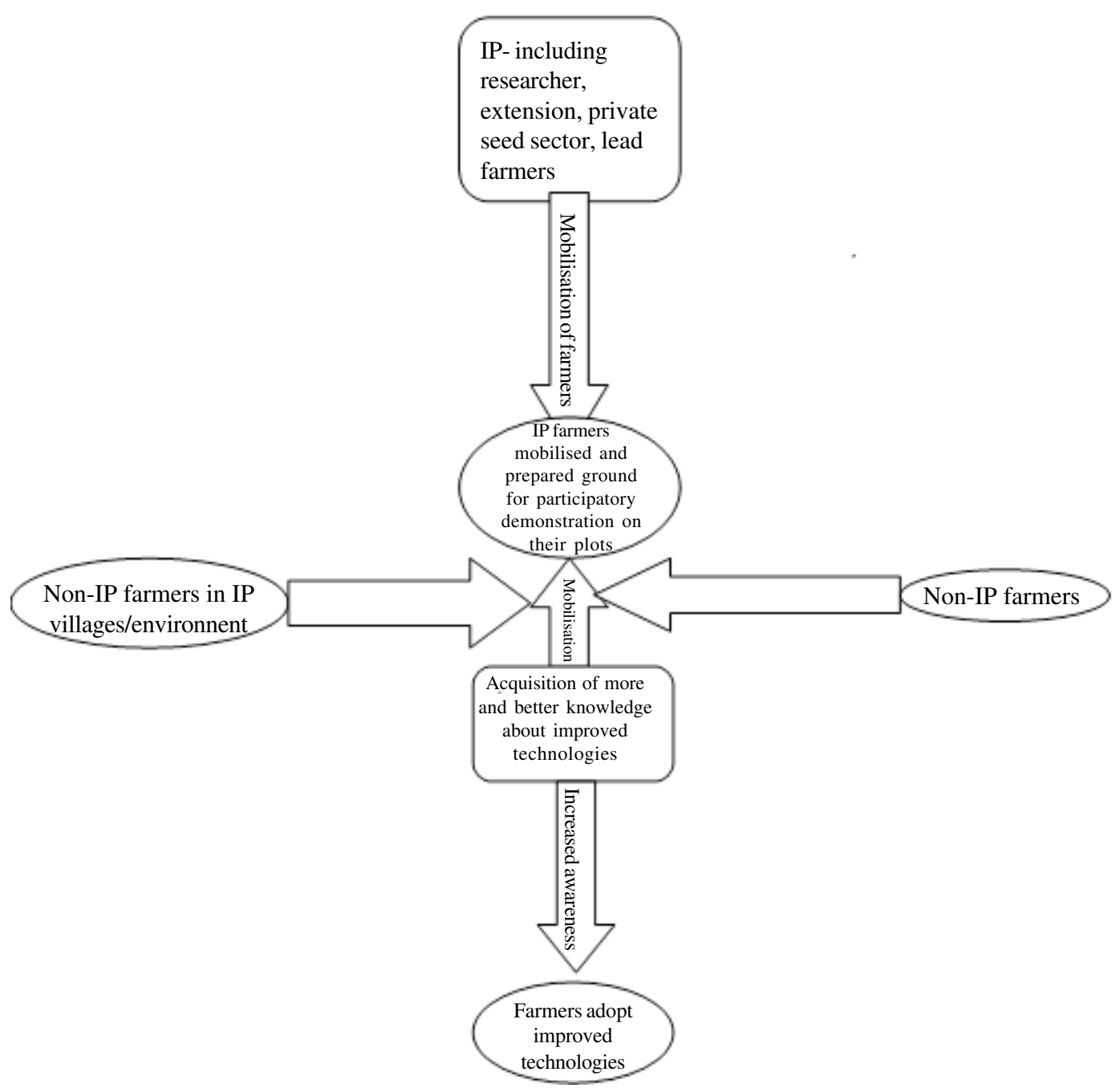

Figure 1. Agricultural technology pathway in the Kano-Katsina-Maradi Pilot Learning Site.

programme targeting and participation, and the assumptions are crucial to developing the appropriate model to determine programme impacts. Among others, these methods include randomised evaluations, matching methods (specifically propensity score matching-PMS), instrumental variable (IV) and regression discontinuity (see further discussion on these methods in Baker, 2000; Khandker et al., 2010). In this paper, we apply the method of Instrumental Variable (IV).

In the method of IV, the basic evaluation problem comparing, say outcomes $Y$ (adoption of agricultural technologies in our case) across treated (IP/IAR4D farmers) and nontreated (clean and conventional farmers) individuals $i$ can be represented as:

$Y_{i}=\alpha X_{i}+\beta T_{i}+\varepsilon_{i}$ Equation 1

Where: $T$ is a dummy equal to 1 for those who participate, and 0 for those who do not participate. $X$ is a set of other observed characteristics of the individual and perhaps of his or her household and local environment. 
Finally, $\varepsilon$ is an error term reflecting unobserved characteristics that also affect $Y$.

Equation 1 reflects an approach commonly used in impact evaluations, which is to measure the direct effect of programme $T$ on outcomes $Y$. Indirect effects of the programme (that is, those not directly related to participation) may also be of interest, such as changes in prices within programme areas.

The problem with estimating by Equation 1 is that treatment assignment is not often random because of (a) purposive programme selection and (b) self-selection into the programme. That is, programmes are placed according to the needs of the community and individuals, who in turn self-select given programme and placement. Self-selection could be based on observed characteristics, unobserved factors, or both.

In the case of unobserved factors, the error term in the estimating equation will contain variables that are also correlated with the treatment dummy $T$. One cannot measure and therefore account for these unobserved characteristics in Equation 1, which leads to unobserved selection bias. If treatment assignment $T$ is random in Equation 1 above, selection bias is not a problem at the level of randomisation. However, treatment assignment may not be random because of two broad factors. First, "endogeneity" may exist in programme targeting or placement, that is, programmes are placed deliberately in areas that have specific characteristics that may or may not be observed; and that are correlated with outcomes $Y$. Second, "unobserved individual heterogeneity" stemming from individual beneficiaries' self-selection into the programme also confounds an experiment set up. Self-selection bias which may result from both of these factors because of the unobserved characteristics in the error term will contain variables that also correlate with the treatment dummy $T$. That is, $\operatorname{cov}(T$,

) 0 implies violation of one of the key assumptions of OLS in obtaining unbiased estimates: independence of regressors from the disturbance term $\varepsilon$. The correlation between $T$ and $\varepsilon$ naturally biases the other estimates in the equation, including the estimate of the programme effect $\beta$.

As we pointed out earlier, one of the methods which have been found to address and capture the effects of some of these problems is the IV methods (Angrist and Imbens, 1991; Abadie, 2003; Imbens and Wooldridge, 2009; Khandker et al., 2010). The IV method aims to clean up the correlation between $T$ and $\varepsilon$; that is, the variation in $T$ that is uncorrelated with $\varepsilon$ need to be isolated. To do so, one needs to find an instrumental variable, denoted by $Z$, that satisfies the following conditions: (a) correlated with $T$ : cov $(Z, T) 0$; (b) uncorrelated with $\varepsilon$ : $\operatorname{cov}(Z, \varepsilon)$ $=0$. Thus instrument $Z$ affects selection into the programme, but is not correlated with factors affecting the outcomes (also known as exclusion restriction).

The theoretical framework which forms the basis of analysis in this research can be represented as follows: Given that we are evaluating participation in research demonstration within the concept of the SSA CP's IP, let $Y_{i}$ represent the adoption of technology for household $i$. Furthermore, let $T_{i}=1$ for participants and the value of $Y_{i}$ under treatment be represented as $Y_{i}(1)$. For nonparticipants, $T_{i}=0$ and $Y_{i}$ can be represented as $Y_{i}(0)$. If $Y_{i}(0)$ is used across nonparticipating households as comparison outcomes $Y_{i}(1)$, the average effect of the programme might be represented as follows:

$$
D=E\left(Y_{i}(1) \mid T_{i}=1\right)-E\left(Y_{i}(0) \mid T_{i}=0\right)
$$
Equation 2

The problem is that the treated and the nontreated groups may not be the same prior to the intervention. Therefore, the expected difference between those groups may not be due entirely to programme intervention. In Equation 2, we can specify the expected counterfactual outcome (outcome for nonparticipants if they had participated in the 
programme) as $\mathrm{E}\left(Y_{i}(0) \mid T_{i}=1\right)$. Another way of specifying this is expressed in Equations 3 -5 :

$D=E\left(Y_{i}(1) \mid T_{i}=1\right)-E\left(Y_{i}(0) \mid T_{i}=0\right)+\left[E\left(Y_{i}\right.\right.$ (0) $\left.\left.\mid T_{i}=1\right)-E\left(Y_{i}(0) \mid T_{i}=1\right)\right] \ldots$. Equation (3)

$D=A T E+\left[E\left(Y_{i}(0) \mid T_{i}=1\right)-E\left(Y_{i}(0)\right.\right.$ । $\left.\left.T_{i}=0\right)\right] \ldots \ldots \ldots \ldots \ldots \ldots \ldots \ldots . . . \ldots$ Equation 4

$D=A T E+B \ldots \ldots \ldots \ldots \ldots \ldots$ Equation

Where: Equations, $A T E$ is the average treatment effect $\left[E\left(Y_{i}(l) \mid T_{i}=1\right)-E\left(Y_{i}(0) \mid\right.\right.$ $\left.T_{i}=1\right)$ ], namely, the average gain in outcomes of participants relative to nonparticipants, as if nonparticipating households were also treated. The ATE corresponds to a situation in which a randomly chosen household from the population is assigned to participate in the programme, so participating and nonparticipating households have an equal probability of receiving the treatment $T$.

The term $B,\left[E\left(Y_{i}(0) \mid T_{i}=1\right)-E\left(Y_{i}(0)\right.\right.$ । $\left.\left.T_{i}=0\right)\right]$, is the extent of selection bias that crops up in using $D$ as an estimate of ATE. Because one does not know $E\left(Y_{i}(0) \mid T_{i}=1\right)$, one cannot calculate the magnitude of selection bias. As a result, if one does not know the extent to which selection bias makes up $D$, one may never know the exact difference in outcomes between the treated and the control groups. Our preceding discussion on how instrumental variable can resolve selection bias in participation, programme placement, or both suffices in meeting this challenge (Rosenbaum and Rubbin, 1983; Lechner, 1999).

We define the key variables that are appropriate for our data and how we intend to apply them in the analysis. We employ as our treatment, $D$ which is 'participation' in research demonstration by farmers.

Participation in research demonstration in the KKM PLS is induced by the IAR4D (which affects and motivate farmer groups' participation in the community mobilisation

where technology demonstration takes place), because community mobilisations are organised by the three different task forces towards the start of every cropping season to sensitise farmers on various aspects of technologies that are promoted within the IP. Our outcome $Y$ takes the value of 1 or 0 for adoption or not adoption of the technologies that are demonstrated. We use as instrumental variable $Z$, group membership which the 5 IAR4D influences. We submit that since attendance at IP meetings take the form of farmers' and other stakeholders' group representation, discussions and deliberations at the IP meetings result into information sharing. This, in turn motivates participation at the community mobilisation, where the technologies are demonstrated. The technology adoption that we are investigating include among others, crop varieties, soil erosion control structures, agroforestry, soil fertility improvement, crop protection, postharvest handling, tillage methods, plant spacing and multiplication of seed/planting materials.

Sampling and data. The data were taken from a cross-sectional midline survey of 1800 households across KKM PLS. The survey, which was conducted in 2010/2011, covers a total of 180 villages in 3 Task Forces (TFs). These included the Northern Guinea Savanna (NGS), the Sahel Savanna (SaS) and the Sudan Savanna (SS). Multistage stratified random sampling procedures had (earlier at the inception of implementation of the SSA CP) been applied and carried out in the three TFs within the previously selected districts (IAR4D and counterfactual) to select the villages where the treatment were being applied, that is villages where IAR4D were introduced, village/ communities where conventional approaches were in operation, and villages where no interventions had been carried out over the last 2-5 years.

The data used for analysis in this paper are representatives of the conditions of the implementation-midline of the three task forces 
that constitute the KKM PLS. These conditions were captured using a set of questionnaires, which included the household and plot levels. The data used consist of variables such as socio-economic and demographic characteristics, farmer participation in research demonstration and adoption of the demonstrated technologies. Specifically for this study, variables of primary importance included whether a household participated in agricultural research or extension demonstration plot or not; if household did, type of technology being demonstrated that the household participated in.

Nine types of technology being demonstrated were identified as (i) crop varieties, (ii) soil erosion control structures, (iii) agroforestry, (iv) soil fertility improvement, (v) crop protection, (vi) postharvest handling, (vii) tillage methods, (viii) plant spacing, and other management practices, (ix) multiplication of seed/planting materials. These technology types were recategorised into 3 main groups, based on the order in which they selected for participation by groups of farmers (this grouping is shown alongside its discussion in Table 3 ).

Other variables of primary importance included distance to research site from homestead, who decided on the technologies to be researched/demonstrated, role in the research/demonstration, perception on the usefulness of the research/demonstration, adoption or not of the demonstrated technologies and reasons for not adopting. Socio demographic/economic and institutional variables were included in the impact model in the determination of the impact estimates. The summary statistics of these variables are shown on Table 1 and described below.

In determining the impact of participation in research demonstration on farmers' adoption of agricultural technologies, participation was modeled as a choice variable, and the determinants of participation and those of the instrument were identified. Our instrumental variable was IP group membership; IP group membership is influenced by the IAR4D- attendance at IP meetings, which takes the form of farmers' and other stakeholders' group representation. IP Group membership is considered an appropriate instrument because the research demonstration is carried out within the IP setting. It is also evident that members of these groups will be privelged to partake in the technology demonstration. Furthermore, most of the issues relating to agricultural innovation and technology promotion are discussed in the IP meetings mainly for the sake and benefit of the IP stakeholders.

The relevance of the IP group membership as a valid instrument can be seen in its correlation with participation and it only affects adoption through the treatment variable. The treatment (participation) is then used as a regressor with other socio-demographic/ economic covariates. Some institutional variables, e.g. membership in farmer association, credit access, access to input and output markets, proximity to output market, access to extension services, frequency of extension visits, and village contact with research organisations, were also included. These variables were expected to influence participation and adoption. Household covariates such as IAR4D (respondent living in IP village) age, education, gender, household size, total farm size, farming and experience were included in the instrument model. Also included in the instrument model were institutional variables (especially other associations besides the IP groups). Some of the variables included in the instrument model were likely to affect participation. Control variables such as participation, age, education, gender, household size, total farm size, farming experience, membership of association, proximity of input market, access to output market, access to credit and frequency of extension visit by household were used for the adoption model. Though some of these variables had been included in the participation and instrument model, many of them are expected to influence adoption. 
RESULTS AND DISCUSSION

Farmers' viewpoints on Technology demonstrated. Tables 2-5 show the viewpoints of households on the technologies that were researched on and demonstrated. On who decided on the technologies to be demonstrated, $67 \%$ of IP farmers and 59\% of non-IP farmers gave responses as researchers/ extension officers. We also have the following responses on the above (researchers/extension in consultation with farmers: IP $=18 \%$, non$\mathrm{IP}=18 \%$ ); (researchers, extension and farmers agreed: $\quad \mathrm{IP}=20 \%$, non-IP $=12 \%$ ); (farmers: $\mathrm{IP}=3 \%$, non-IP $=2 \%$ ); (cooperatives: $\mathrm{IP}=1 \%$, non-IP $=0 \%$ ). About farmers' perception on the usefulness of the research/demonstration, the following responses were gathered from the respondents: Not useful (IP=2\%, non-IP $=2 \%$ ), somehow useful ( $\mathrm{IP}=5 \%$, non-IP $=5 \%)$, useful (IP $=50 \%$, non-IP $=41 \%)$, very useful (IP $=52 \%$, non-IP $=43 \%)$. Some respondents did not to adopt some of the technologies that were demonstrated. They gave reasons to be lack of planting materials (IP $=40 \%$, non$\mathrm{IP}=57 \%$ ), research not useful ( $\mathrm{IP}=4 \%$, non$\mathrm{IP}=7 \%)$, lack of land ( $\mathrm{IP}=0$, non-IP $=0)$, lack of inputs (IP $=29 \%$, non-IP $=52 \%)$, lack of labour ( $\mathrm{IP}=2 \%$, non- $\mathrm{IP}=7 \%)$. The results underscore the importance of participatory approach in agricultural technology development. Lilja and Dixon (2011) asserted that Participatory plant breeding (PPB) and participatory natural resource management (PNRM) emerged in early 1980's as a potential solution to the problem of limited adoption of varieties and natural resource management technologies by farmers in developing countries. This assertion had earlier been proven by Farrington (1998) and Ashby (2003); and there is empirical evidence in support of its effectiveness in terms of improved farmer acceptance of crop varieties and resource management techniques (Witcombe 1999; Ceccarelli et al., 2001; Bellon et al., 2003; Ceccarelli et al., 2003; Dorward 2003; Ortiz, 2004) and impact
(Onduru et al., 2002; Johnson et al., 2003; Joshi et al., 2003; Smale, 2003; Dalton et al., 2005). Accordingly, one explanation that was offered for why PPB and PNRM methods might increase adoption was that incorporating farmers varietal preferences and environmental constraints into the process of designing and developing varieties and resource management options increases the probability that these technologies will be relevant and appropriate. This indicates that greater use of participatory approaches in agricultural research has significant implications for impact assessment.

Type of research demonstration. In technology Group 1, about $73 \%$ of IP farmers participated in the demonstration of crop varieties (Table 6), $10.85 \%$ in plant spacing and other management practices and $7.75 \%$ in soil fertility improvement, while 70.19, 9.13 and $9.135 \%$ of the non-IP farmers participated in crop variety, soil fertility and plant spacing and other management practices, respectively.

On the participation of the respondents in the demonstration of technology Group 2, results show that $25.61,23.17$ and $17.07 \%$ of IP farmers participated in the demonstration of soil fertility improvement, crop protection and plant spacing and other management practices, respectively; while 35.54, 21.49 and $14.05 \%$ of the non-IP farmers participated in soil fertility improvement, crop protection and post-harvest handling, respectively. Results on technology Group 3 show that 43.43, 21.67 and $13.33 \%$ of IP farmers participated in the demonstration of plant spacing and other management practices, crop protection and soil fertility improvement. Also in the demonstration of technology Group 3, 53.63, 12.05 and $9.64 \%$ of the non-IP farmers participated in the demonstration of plant spacing and other management practices, crop variety and soil fertility/crop protection respectively. Overall, we observed that larger percentage of households participated in the demonstration of the following technology types: crop varieties, plant spacing, soil fertility 
TABLE 1. Descriptive statistics of the sampled households in relation to the variables included in the impact model

\begin{tabular}{|c|c|c|c|c|}
\hline Variable & Description & $\begin{array}{l}\text { Treated } \\
(\mathrm{n}=588)\end{array}$ & $\begin{array}{l}\text { Untreated } \\
(\mathrm{n}=1157)\end{array}$ & $\begin{array}{l}\text { Total sample } \\
(\mathrm{n}=1745)\end{array}$ \\
\hline Treatment & Participation in research activities & 0.23 & 0.20 & 0.21 \\
\hline Instrument & IP (Iar4d) Group membership & 0.03 & 0.04 & 0.043 \\
\hline Outcome variable & Adoption of demonstrated technologies & 0.20 & 0.17 & 0.18 \\
\hline \multicolumn{5}{|l|}{ Socio-demographic/economic } \\
\hline Gender & 1 if household head is male, 0 otherwise & 0.97 & 0.96 & 0.97 \\
\hline Education & 1 if household head has formal education, 0 otherwise & 0.48 & 0.44 & 0.45 \\
\hline Age & Age of household head (years) & 49.45 (13.37) & $49.76(13.18)$ & $49.66(13.24)$ \\
\hline Household size & Number of people living with household head & $12.59(6.62)$ & $12.51(6.49)$ & $12.54(6.53)$ \\
\hline Iar4d & 1 if respondent lives in IP village, 0 otherwise & $0.03(0.18)$ & $0.04(0.20)$ & $0.4(0.19)$ \\
\hline Total area under cultivation & Total area under cultivation for all crops (hectares) & $7.10(6.60)$ & $7.17(7.87)$ & $7.16(7.46)$ \\
\hline Farming experience & Farming experience of household head & $26.63(14.21)$ & $27.08(3.68)$ & $26.93(13.86)$ \\
\hline \multicolumn{5}{|l|}{ Institutional variables } \\
\hline Membership in farmer associations & 1 if household head belongs to an association, 0 otherwise & 0.28 & 0.27 & 0.28 \\
\hline Credit access & 1 if household has access to credit, 0 otherwise & 0.01 & 0.01 & 0.01 \\
\hline Access to input & 1 if household has access input, 0 otherwise & 0.45 & 0.36 & 0.39 \\
\hline Proximity to input market & Average distance to input market from household & $3.30(7.89)$ & $3.22(9.67)$ & $3.25(9.11)$ \\
\hline Access to output market & 1 if household has access to output market, 0 otherwise & 0.75 & 0.70 & 0.72 \\
\hline Access to extension services & 1 if household received extension, 0 otherwise & 0.28 & 0.29 & 0.29 \\
\hline Frequency of extension visits & Average number of times household received extension visit & $1.17(2.51)$ & $1.12(2.40)$ & $1.14(2.44)$ \\
\hline Village contact with research organisations & 1 if village Has contact with research organizations, 0 otherwise & 0.08 & 0.074 & 0.077 \\
\hline Research demonstration distance & Average distance of demonstration site to household & $2.15(14.57)$ & $1.24(8.56)$ & $1.55(10.96)$ \\
\hline Village contact with extension organisations & 1 if village Has contact with extension organizations, 0 otherwise & 0.09 & 0.092 & 0.092 \\
\hline
\end{tabular}

Values in brackets represent standard deviation 
TABLE 2. Who decides on the research to be demonstrated?

\begin{tabular}{lcc}
\hline Actor & \multicolumn{2}{c}{ Farmers } \\
\cline { 2 - 3 } & IP $(\%)$ & Non-IP (\%) \\
\hline Researcher/extension officers & 67 & 59 \\
Researcher/extension in consultation with farmers & 18 & 18 \\
Researchers, extension and farmers agreed & 20 & 12 \\
Farmers & 3 & 2 \\
Cooperatives & 1 & 0 \\
\hline
\end{tabular}

TABLE 3. Role in the research demonstration played by farmers in the KKM PLS (Nigeria and Niger Republic)

\begin{tabular}{lcc}
\hline Role & \multicolumn{2}{c}{ Farmers } \\
\cline { 2 - 3 } & IP $(\%)$ & Non-IP (\%) \\
\hline Just watched and learned & 64 & 61 \\
Provided labour & 11 & 0.8 \\
Collected data & 24 & 24 \\
Made decision on the research & 1 & 1 \\
Others & 3 & 2 \\
\hline
\end{tabular}

TABLE 4. Perception of usefulness of the research demonstration in the KKM PLS (Nigeria and Niger Republic)

\begin{tabular}{lcc}
\hline Participation & \multicolumn{2}{c}{ Farmers } \\
\cline { 2 - 3 } & IP $(\%)$ & Non-IP (\%) \\
\hline Not useful & 2 & 2 \\
Somehow useful & 5 & 5 \\
Useful & 50 & 41 \\
Very useful & 52 & 43 \\
\hline
\end{tabular}

TABLE 5. Reasons for non- adoption of the technologies demonstrated in the KKM PLS (Nigeria and Niger Republic)

\begin{tabular}{lrc}
\hline Reason & \multicolumn{2}{c}{ Farmers } \\
\cline { 2 - 3 } & IP $(\%)$ & Non-IP (\%) \\
\hline Lack of planting material & 40 & 57 \\
Research not useful & 4 & 7 \\
Lack of land & - & - \\
Lack of inputs & 29 & 52 \\
Lack of labour & 2 & 7 \\
\hline
\end{tabular}


management and crop protection. Though households participated in the demonstration of all the technology types, the four types mentioned appear to be very important to most of the households.

Many studies on participatory research have been based on crop varietal selection and plant breeding. Few of these studies include Conroy and Sutherland (2004), Lilja and Bellon (2006) and Ghimire (2009). Though they showcased the importance of other supporting technologies that are complementary to the crop varietal selection and breeding, the present study has been able to clearly show that the order of the quantum in which the households participated in the research demonstration can be matched with their preferences for participation. This also is an indication that farmers in the study area are actually aware of the implications of making appropriate decisions on the types of crops that suit their soil environment in terms of crop varieties, how to apply the knowledge of plant spacing and other management practices, soil fertility management and thereafter how to protect the crops from pest and diseases.

Determinants of participation in research demonstration. Probit estimations of the determinants of participation in research demonstration in the KKM PLS are given in Table 7. We also estimate the marginal effects of the variables included in the Probit model in order to predict the probabilities of some of the factors to either increase or reduce participation. Participation in research demonstration is explained significantly by being an IP farmer, formal education, membership in farmer association, distance to research/technology demonstration site and village and household access to extension services. All significant variables have the expected signs, except distance to the research site. Contrary to expectations, longer distances to the research site increased the probability of participation by about $2 \%$. Hypothetically, the expected sign of the coefficient is negative, which means an increase in the magnitude of 
TABLE 7. Probit model estimation of the determinants of participation and marginal effects

\begin{tabular}{lcccc}
\hline Explanatory variables & Coefficients & Standard Error & Marginal effects & Standard Error \\
\hline IAR4D & $1.207^{* * *}$ & 0.180 & $0.428^{* * * *}$ & 0.069 \\
Gender & -0.013 & 0.206 & -0.004 & 0.054 \\
Age of household head & 0.004 & 0.003 & 0.001 & 0.001 \\
Education of household head & $0.189^{*}$ & 0.082 & $0.050^{* * *}$ & 0.022 \\
Membership of association & $0.654^{* * *}$ & 0.082 & $0.192^{* * * *}$ & 0.026 \\
Research distance & $0.094^{* * *}$ & 0.009 & $0.024^{* * *}$ & 0.003 \\
Village access to extension services & $0.308^{*}$ & 0.121 & $0.089^{* *}$ & 0.038 \\
Access to inputs & 0.147 & 0.078 & $0.039^{*}$ & 0.021 \\
Access to extension & $0.629^{* * *}$ & 0.080 & $0.183^{* * *}$ & 0.025 \\
Constant & $-.0802^{* * *}$ & 0.270 & & \\
Number of observation & 1773 & & & \\
LR chi2 (9) & 470.49 & & & \\
Prob > chi2 & 0.0000 & & & \\
Pseudo R2 & 0.2587 & & & \\
Log likelihood & -674.23508 & & & \\
\end{tabular}

the explanatory variable, i.e. distance to research demonstration site would result in a decrease in the response variable, i.e. participation in research demonstration. Conversely, we expect shorter distances to improve participation. We have expected easy access in form of shorter distance to the research site to be a source of encouragement to prospective participating farmers to take part in the research technology demonstration. It could be that these variables, distance to research demonstration site and village access to extension services are correlated.

The IAR4D, which the SSA CP is spearheading, appears to be creating a lot of awareness in terms of agricultural innovations, which is promoting technology. This seems to be very effective in promoting participation in research demonstration. Being an IAR4D/ IP farmer increases the probability of participation by about $43 \%$ (Table 7). Literate households are more likely to participate in research demonstration by a probability of $5 \%$. Literate households should have better access to information and be more able to process information and understand the importance of participating in agricultural technology demonstration. Membership to farmer associations, village and household access to extension and access to inputs are all likely to improve participation by about 19, 9 and 18, and $4 \%$ respectively.

In highlighting the indicators of participation of stakeholders in agricultural and rural development projects, Karl (2000) in his study, which evaluated stakeholder participation in agricultural and rural development projects, opined that there were no generic indicators of participation. He, however, revealed that indicators selected will vary according to the project and its objectives. Accordingly, literature (Bhatnagar and Williams, 1992) proposed three very broad categories of indicators as (i) empowerment indicators, e.g. how many new initiatives were launched? How proactive the group was, as measured against a specially devised index? (ii) indicators of continuity and participation; and (iii) autonomy indicators. According to Karl (2000), development agencies like DFID (1995a; 1995b) had drawn up categories or questions that can be used in developing indicators. These categories are of the extent and quality of participation and these include quantifiable indicators. These are economic and organisational indicators of participation, participation in project activities and development momentum. There are also 
qualitative indicators like organisational growth, group behaviour and group selfreliance.

In as much as we cannot adequately boast of a prototype set of indicators of participation in research demonstration for agricultural technology development to aid the adoption of same by smallholder households, our results appear to provide an indication of the socioeconomic and institutional factors that the SSA CP can enhance to improve upon the participation of smallholders in research demonstration that will drive the technology adoption.

Determinants of adoption of the technologies. The nonlinear least square results for the determinants of the adoption of the demonstrated technologies are presented in Table 8. The model diagnostic statistics given, which include an adjusted $R^{2}$ of about $71 \%$, indicate a good fit of the function. Results show that participation in the research demonstration positively and significantly determined the adoption of the technology demonstrated. Farming experience also positively and significantly determined adoption.

Age of the household head, formal education, and gender were all negatively significant. Most of the institutional variables (except credit access and frequency of extension visit) were significant determinants of the adoption of the demonstrated technologies.

Contrary to expectation, however, proximity to input market did not hinder adoption of the demonstrated technologies. This implies that farmers who participated in research demonstrations found the technologies useful. The negative and significant coefficient of the variable on distance to output market was expected, and this is an indication that easy access to these output markets in terms of short distances encouraged participants to adopt the demonstrated technologies. It also indicates the importance of linkage of farmers to markets for the disposal of their products after harvesting.

The SSA CP has taken this up within the framework of the Innovation Platform system.

TABLE 8. Nonlinear least square estimation of the determinants of adoption of the demonstrated technologies in the KKM PLS (Nigeria and Niger Republic)

\begin{tabular}{llc}
\hline Explanatory variables & Coefficients & Standard Error \\
\hline Participation & $2.29 * * *$ & 0.07 \\
Age of household head & $-0.04^{* * *}$ & 0.002 \\
Education of household head & $-0.07^{* *}$ & 0.033 \\
Gender & $-0.49^{* * *}$ & 0.05 \\
Household size & 0.003 & 0.002 \\
Total farm size & 0.002 & 0.002 \\
Farming experience & $0.005^{* * *}$ & 0.002 \\
Membership of association & $0.13^{* * *}$ & 0.031 \\
Average distance to input market & $0.003^{* *}$ & 0.001 \\
Average distance to output market & $-0.072^{* *}$ & 0.033 \\
Access to credit & 0.014 & 0.10 \\
Frequency of extension visit & 0.002 & 0.004 \\
Number of observation & 1766 & \\
R-squared & 0.7157 & \\
Adjusted R-squared & 0.7136 & \\
Root MSE & 0.2250 & \\
Res. dev. & -270.5679 & \\
\hline
\end{tabular}


The various task forces have included in their IP activities, linkage of the farmers to input and output market. This has also been clearly emphasized in the SSA CP's research plan (FARA, 2009). Although some of the hypothesized variables determine adoption, in our study they appear not be in consonance with some conventional expectation of factors influencing adoption, we observe that literature supports the significance of most of the important findings in our study of participatory research demonstration. For example, Gebremedhin et al. (2009) examined the role of institutional services of credit, input supply and extension in the overall commercial transformation process of smallholder agriculture in Ethiopia. It was found that strengthening the existing notion that smallholders' access to well integrated institutional support services is crucial in getting farmers to participate both in input and output markets. This was in order to get better income through intensified and market oriented agriculture.

Exploring better ways of empowering smallholders to have unfettered access to these markets in term of good motorable roads is a policy issue which the SSA CP can take up with the decision (policy) makers where the IPs are located. Also in our study, farming experience and membership of association significantly determined adoption (Table 8 ) in the context of the technologies that were demonstrated by the IP.

Traditional determinants of adoption have been found to include farming experience (Tiamiyu et al., 2009), and sometimes, membership of farmer association. In this case "farming experience" was described as a factor which is expected to demonstrate increasing returns up to a stage and later diminishing return. This is because more elderly farmers have been reported to be more risk averse when they will be less likely to experiment with new technologies. This can be adduced as the reason why age is negatively and significantly a determinant of adoption in our study. In the case of the variable "membership of farmer association", the following can be deduced: Increase in the farmers' access to information on various technologies through membership of associations has been shown to influence adoption decisions. This is achieved either through training or sharing of knowledge and experience and fostering of collective action.

In this way, internalising risks associated with new innovations by having farmers learn and share experiences about the technologies is ensured. It is also asserted that performing certain functions such as group marketing are some of the ways through which membership in farmer organisation can influence adoption of agricultural technologies.

\section{Impact of participatory demonstration.}

Table 9 presents results for the impact of participation in research demonstration on technology adoption. Results which are based on the Inverse Propensity Score Weighting, method indicate that participation in research demonstration significantly increases adoption of the demonstrated technology by $99 \%$ (Table 9). Furthermore, results show that participation in research demonstration significantly increases technology adoption by 100 and $99 \%$.

Generally, participation in research demonstration impacted positively on the adoption of the technologies which the SSA

TABLE 9. Inverse propensity score weighting parameter estimated

\begin{tabular}{lcccc}
\hline Parameters & Coefficients & Robust Standard Error & $\mathrm{Z}$ & $\mathrm{P}>|\mathrm{z}|$ \\
\hline Ate & 0.99 & 0.04 & 25.30 & 0.000 \\
ate & 1.0 & 0.06 & 16.36 & 0.000 \\
Ate0 & 0.99 & 0.04 & 25.37 & 0.000 \\
\hline
\end{tabular}


$\mathrm{CP}$ has been promoting in the KKM PLS task forces (Table 9). In all cases, the impact of participation was above average. Though the research demonstrations were mainly organised by the IPs and for the IP farmers, they were not a "close door" activities to other farmers who found time to witness the research demonstration activities. As such, the nonparticipating farmers appear to have devoted more attention to the demonstrated technologies and are more determined in their adoption. We can begin to see this as one of the initial "spill-over" effects of the SSA CP's IAR4D. In all, the research demonstrations that the IP systems of the KKM PLS conducted had positive impact on the adoption of the promoted agricultural technologies. This is evidence of the impact of the IAR4D approach that the SSA CP is experimenting. Adoption of the promoted technologies can be improved upon and full adoption attained if the socioeconomic and institutional variables that have been discovered to influence participation, are strengthened. This means that increased participation of smallholders in research demonstrations will translate into more adoption of the SSA CP's promoted technologies as shown by the positive and significant effect of participation on adoption. However, other demographic, socioeconomic and institutional factors have to be taken into consideration.

\section{CONCLUSION}

Though, participation in research demonstration has had positive and significant impact on the adoption of the promoted technologies, our findings indicate that both participation and adoption could be improved if the socioeconomic and institutional factors that influence them can be strengthened. For example, participation was positively and significantly determined by being an IAR4D/ IP farmer, formal education, membership of farmer association, research distance, village and household access to extension. This means that these factors are important in effecting more participation in research demonstration. With the exception of research distance, which is also positively significant in determining participation, the SSA CP can together with the policy makers of the IPs, find the possibilities of effecting some modifications in the IAR4D/IP membership to the extent that this will encourage more smallholders to be engaged through group membership activities, access to extension and research institutions. In the case of research distance, we have postulated that shorter distances to research demonstration site will result into more participation and vice versa. We observed a positive and significant coefficient, which means that the longer the distance to research site, the likelihood that more farmers will participate. This, as we noticed, could be due to the fact that the technologies being promoted and demonstrated by the IPs are crucial to the livelihood of smallholders and will make every effort to participate in the technology demonstration. Be that as it may, we see the issue of distance to the research demonstration site as a crucial and very important policy issue. What is important is not the physical distance, but what we can call the "economic distance" to the smallholder. Many of the rural feeder roads are in terrible conditions and this negatively affects movement of smallholders to the research demonstration sites. It also negatively affects access to both input and output markets. In effect, ensuring that the rural roads become motorable is what the policy elements (LGAs) of the IPs should tackle.

In the case of adoption, factors like participation, farming experience, membership of farmer group, distances to both input and output markets are important determinants of adoption. These factors influence adoption and are likely to cause increase in adoption if they are strengthened. With the exception of farming experience, the other factors here are crucial and policy issues that will encourage smallholders to belong to farmer group and therefore create motivation to participate in the IAR4D are important. 


\section{ACKNOWLEDGEMENT}

The authors gratefully acknowledge the support of the Forum for Agricultural Research in Africa (FARA) in funding the midline survey of the sub-Saharan Africa Challenge programme (SSA CP) from which the data used for this study was made possible.

\section{REFERENCES}

Abadie, A. 2003. Semiparametric instrumental variable estimation of treatment response Models. Journal of Econometrics 113: 231 - 263.

Angrist, J.D. and Imbens, G. W. 1991. Identification and estimation of local average treatment effects. Technical Working Paper No. 118.

Ashby, J. 2003. Introduction: Uniting science and participation in the process of innovation-Research for Development. In: Managing natural resources for sustainable livelihoods, uniting science and participation. Pound, B., Snapp, S., McDougall, C. and Braun, A. (Eds.). London: Earthscan.

Ashby, J.A. 1996. What do we mean by participatory research in agriculture? In: New frontiers in participatory research and gender analysis. Proceedings of the International Seminar on Participatory Research and Gender Analysis (PRGA), 914 September 1996, Cali, Colombia. Centro Internacional de Agricultura Tropical (CIAT) Publication No. 294. pp. 15-22.

Baker, J.L. 2000. Evaluating the impacts of development projects on poverty: A Handbook for Practitioners. The World Bank. Washington D.C., USA.

Bellon, M.R., Berthaud, J., Smale, M., Aguirre, J.A., Taba, S., Aragon, F., Diaz, J. and Castro, H. 2003. Participatory landrace selection for on-farm conservation: An example from the Central Valleys of Oaxaca, Mexico. Genetic Resources and Crop Evolution 50: 401-416.
Bhatnagar, B. and Williams, A.C. 1992. Participatory development and the World Bank: Potential directions for change, World Bank Discussion Paper 183, The World Bank. Washington D.C.:, USA.

Biggs, S. and Smith, S. 2003. Paradox of learning in project cycle management and the role of organizational culture. World Development 31(10):1743-1757.

Biggs, S.D. 1989. Resource-poor farmer participation in research: A synthesis of experiences from nine national agricultural research systems. OFCOR Comparative Study Paper No. 3. International Service for National Agricultural Research (ISNAR), The Hague, The Netherlands.

Biggs, S.D. and Farrington, J. 1991. Agricultural Research and the Rural Poor: A Review of Social Science Analysis. International Development Center (IDRC), Ottawa, Canada.

Buchy, M., Ross, and Proctor, W. 2000. Enhancing the information base on participatory approaches in Australian natural resources management. Research Report in the Series: Natural Resources Management - People and Policy. Camberra, Australia: Researchfrom the Social and Institutional Research Program of the Land and Water, Australia, Canberra.www.socialcapitalresearch.com/ ...social.../reference-list-participationtheories.html

Byerlee, D. and Heisey, P. 1996. Past and potential impacts of maize research in subSaharan Africa: A critical assessment. Food Policy 21: 255-277.

Cameron, A.C. and Trivedi. P.K. 2005. Microeconometrics: Methods and Applications. Cambridge University Press, New York, USA.

Campbell, J.R. 2001. Participatory rural appraisal as qualitative research: Distinguishing methodology issues from participatory claims. Human Organization 60(4): 380-389. 
Ceccarelli, S., Grando, S., Bailey, E., Amri, A., El-Felah, M., Nassif, F., Rezqui, S. and Yahyaoui, A. 2001. Farmer participation in barley breeding in Syria, Morocco and Tunisia. Euphytica 122: 521-536.

Ceccarelli, S., Grando, S., Tutwiler, R., Baha, J., Martini, A.M., Salahieh, H., Goodchild, A. and Michael, M. 2003. A methodological study on participatory plant breeding. II Response to selection. Euphytica 133: 185200.

Chambers, R.G. 1988. Applied Production Analysis. New York: Cambridge University Press, USA.

Chambers, R., Pacey, A. and Thrupp, L.A. 1989. Farmers First: Farmer Innovation and Agricultural Research. Intermediate Technology Publications. London, UK.

Chambers, R. 1994. Participatory Research Appraisal (PRA): Challenges, potential and paradigm. World Development 2 (10): 1437-1454.

Chambers, R. 1997. Whose reality counts? Putting the first last. International Technology Publications. London, UK.

Conroy, C. and Sutherland, A. 2004. Participatory technology development with resource-poor farmers: maximizing impact through the use of recommendation domains. ODI Agricultural Research and Network, AgREN Network Paper No 133.

Dalton, T., Lilja, N., Johnson, N. and Howeler, R. 2005. Impact of participatory natural resource managementresearch in cassavabased cropping systems in Vietnam and Thailand. Working Document No. 23 (revised). CGIAR Systemwide Program on Participatory Research and Gender Analysis (PRGA Program), Cali, Colombia. $27 \mathrm{p}$.

Dalton, T. and Guei, R. 2003. Productivity gains from rice genetic enhancements in West Africa: Countries and ecologies. World Development 31(2):359-374.

Department for International Development (DFID), 1995a. Guidance Note on How to Do Stakeholder Analysis of Aid Projects and Programmes, DFID. London, UK.
Department for International Development (DFID). 1995b. Guidance note on indicators for measuring and assessing Primary Stakeholder Participation, London, UK.

Dorward, P., Galpin, M. and Shepherd, D. 2003. Participatory farm management methods for assessing the suitability of potential innovations. A case study on green manuring options for tomato producers in Ghana. Agricultural Systems 75(1): 97-117.

Evenson, R.E. and Gollin, D. (Eds.). 2002. Crop variety improvement and its effect on productivity: The impact of International Research. CAB International, Wallingford, UK.

Farrington, J. 1988. Farmer participatory research: Editorial introduction. ExperimentalAgriculture 24 (3): 269-279.

Farrington, J. 1998. Organizational roles of farmer participatory research and extension: Lessons from the last decade. ODI Bulletin No. 27.

Gaventa, J. 1988. Participatory research in North America. Convergence 21 (2/3): 1927.

Gebremedhin, B., Jaleta, M. and Hoekstra, D. 2009. Smallholders, institutional services, and commercial transformation in Ethiopia. Agricultural Economics 40: 773787.

Ghimire, N.R. 2009. Farmer participation in agricultural development in Nepal: A case study. Agricultural, Food and Environmental Sciences 3 (1): 1-12.

Gonsalves, J., Becker, T., Braun, A., Campilan, D., Chavez, H. D., Fajber, E., Kapirri, M., Rivaca-Caminade, J. and Vernooy, R. 2005. Participatory research and development for sustainable agriculture and natural resource management: A sourcebook. IDRC. Canada.

Imbens, G.M. and Wooldridge, J.M. 2009. Recent developments in the econometrics of programme evaluation. Journal of Economic Literature 47(1):5-86.

Johnson, N., Lilja, N. and Ashby, J.A. 2003. Measuring the impact of user participation 
in agricultural and natural resource management research. Agricultural Systems 78: 287-306.

Johnson, N., Lilja, N., Ashby, J.A. and Garcia, J.A. 2004. The practice of participatory research in natural resource management research. Natural Resources Forum 28: 189-200.

Joshi, K.D. and Witcombe, J.R. 2003. The impact of participatory plant breeding (PPB) on landrace diversity: A case study for high-altitude rice in Nepal . Euphytica 134 (1): 117-125.

Karl, M. 2000. Monitoring and evaluating stakeholder participation in agriculture and rural development projects: a literature review. November 2000, Sustainable Development (SD) Dimensions. Available at: Sustainable Development Department (SD), Food and Agriculture Organization of the United Nations (FAO), h t t p : / / www.fao.org/sd/PPdirect/PPre0074.htm.

Khandker, S.K., Gayatri, K.B. and Samad, H.A. 2010. Handbook on Impact Evaluation: Quantitative Methods and Practices. The World Bank, Washington, D.C., USA.

Lechner, M. 1999. Earnings and employment effects of continuous off-the-job training in East Germany after unification. Journal of Business Economics and Statistics 17 (1): 297-319.

Lilja, N. and Dixon, J. 2011. Responding to the challenges of impact assessment of participatory research and gender analysis. http://www.prgaprogram.org/modules/ downloadsPlus/uploads/PRGA Publications lquito.pdf. Downloaded, November, 2011.

Lilja, N. and Aw-Hassan, A. 2003. Benefits and costs of participatory barley breeding in Syria. Background paper for poster presented at the 25 th International Conference of IAAE, Durban, South Africa, 16-22 August 2003.

Lilja, N. and Bellon, M. 2006. Participatory research projects at the International Maize and Wheat Improvement

Center
(CIMMYT). CGIAR Systemwide Program on Participatory Research and Gender Analysis (PRGA Program), Cali, Colombia and CIMMYT, Mexico, D.F. 43p.

Maredia, M., Byerlee, D. and Pee, P. 1998. Impacts of food crop improvements in Africa. SPAAR Occasional Paper Series No. 1.

Morris, M.L. and Bellon, M.R. 2004. Participatory plant breeding research: Opportunities and challenges for the international crop improvement system. Euphytica 136: 21-35.

Nelson, N. and Wright, S. 1995. Power and participatory development. Intermediate Technology Publication. London, UK.

Nowak, P. 1992. Why farmers adopt production technology. Journal of Soil and Water Conservation 47(1): 14-16.

Okali, C., Sumberg, J. E. and Farrington, J. 1994. Farmer participatory research: Rhetoric and reality. Intermediate Technology Publications. London, UK.

Onduru, D.D., de Jager, A., van der Werf, E. and Diop, J.M. 2002. Participatory on-farm comparative assessment of organic and conventional farmers' practices in Kenya. Biological Agriculture \& Horticulture 19(4): 295-314.

Ortiz, O., Garrett, K. A., Heath, J. J., Orrego, R. and Nelson, R. J. 2004. Management of potato late blight in thePeruvian Highlands: Evaluating the benefits of farmer field schools and farmer participatory research. Plant Disease 88(5): 565-571.

Pretty, J.N. 1994., Alternative systems of inquiry for a sustainable agriculture. IDS Bulletin 25: 37-48.

Rhoades, R.E. 2005. Seeking half our brains: Reflections on the social context of interdisciplinary research and development. In: Understanding culture in agriculture. Cernea, M. and Kasam, A. (Eds.). CAB International. Oxford, U.K.

Roling, N., and Wagemakers, M. A. 1998. A new practice: facilitating Sustainable 
agriculture. In: Facilitating Sustainable Agriculture. Rolling, N.G. and M.A.E. Wagemakers, M.A.E. (Eds.). pp. 3-22. Cambridge University Press, The Edinburgh Building, Cambridge, CB2 8 RU, UK.

Rosenbaum, P.R. and Rubin, D.B. 1983. The central role of propensity score in observational studies for causal effects. Biometrica 70 (1): 41-55.

Smale, M., Bellon, M.R., Manuel, Rosas I., Mendoza, J., Solano, A.M., Martinez, R., Ramirez, A. and Berthaud, J. 2003. The economic costs and benefits of a participatory project to conserve maize landraces on farms in Oaxaco, Mexico. Agricultural Economics 29: 265-275.

Snapp, S.S., Freeman, H.A., Simtowe, F. and Rohrbach, D.D. 2002. Sustainable soil management options for Malawi: Can smallholder farmers grow more legumes? Agriculture, Ecosystems and Environment 91(1/3): 159-174.

Thompson, J. 1995. Participatory approaches in government bureaucracies: Facilitating the process of institutional change. World Development 33 (10):1705-1720

Tiamiyu, S.A., Akintola, J.O. and Rahji, M.A.Y. 2009. Technology adoption and productivity difference among growers of new rice for Africa in the Savanna zone of Nigeria. Tropicultura 27 (4): 193-197.
Weltzein, E., Smith, M. E., Meitzner, L. S. and Sperling, L. 2000. Technical and institutional issues in participatory plant breeding from the perspective of formal plant breeding. A global analysis of issues, results and current experience. CGIAR Systemwide Program on Participatory Research and Gender Analysis (PRGA Program), Cali, Colombia. 199p.

Witcombe, J.R., Joshi A., Joshi K.D. and Sthapit, B.R. 1996. Farmer participatory crop improvement. I. Varietal selection and breeding methods and their impact on biodiversity Experimental Agriculture 32: 445-460.

Witcombe, J.R., Petre, R., Jones, S. and Joshi, A. 1999. Farmer participatory crop improvement. IV The spread and impact of a rice variety identifi ed by participatory varietal selection. Experimental Agriculture 35: 471-487.

Witcombe, J.R., Joshi, K. D., Rana R. B. and Virk, D.S. 2001a. Increasing genetic diversity by participatory varietal selection in high potential production systems in Nepal and India. Euphytica 122(3): 575-588.

Witcombe, J.R . and Virk, D.S. 2001b. Number of crosses and population size for participatory and classical plant breeding. Euphytica 122:451-462. 